\title{
Mindfulness-based stress reduction lowers psychological distress in medical students
}

\author{
Steven Rosenzweig MD \\ Thomas Jefferson University \\ Diane K. Reibel \\ Thomas Jefferson University \\ Jeffrey M. Greeson \\ Thomas Jefferson University \\ George C. Brainard \\ Thomas Jefferson University \\ Mohammadreza Hojat \\ Thomas Jefferson University \\ Follow this and additional works at: https://jdc.jefferson.edu/jmbcimfp \\ Part of the Alternative and Complementary Medicine Commons \\ Let us know how access to this document benefits you
}

\section{Recommended Citation}

Rosenzweig, Steven MD; Reibel, Diane K.; Greeson, Jeffrey M.; Brainard, George C.; and Hojat, Mohammadreza, "Mindfulness-based stress reduction lowers psychological distress in medical students" (2003). Marcus Institute of Integrative Health Faculty Papers. Paper 1.

https://jdc.jefferson.edu/jmbcimfp/1

This Article is brought to you for free and open access by the Jefferson Digital Commons. The Jefferson Digital Commons is a service of Thomas Jefferson University's Center for Teaching and Learning (CTL). The Commons is a showcase for Jefferson books and journals, peer-reviewed scholarly publications, unique historical collections from the University archives, and teaching tools. The Jefferson Digital Commons allows researchers and interested readers anywhere in the world to learn about and keep up to date with Jefferson scholarship. This article has been accepted for inclusion in Marcus Institute of Integrative Health Faculty Papers by an authorized administrator of the Jefferson Digital Commons. For more information, please contact: JeffersonDigitalCommons@jefferson.edu. 


\title{
Mindfulness-Based Stress Reduction Lowers Psychological Distress in Medical Students
}

\author{
Steven Rosenzweig, Diane K. Reibel, Jeffrey M. Greeson, and George C. Brainard \\ Center for Integrative Medicine \\ Jefferson Medical College \\ Philadelphia, Pennsylvania, USA \\ Mohammadreza Hojat \\ Center for Research in Medical Education and Health Care \\ Jefferson Medical College \\ Philadelphia, Pennsylvania, USA
}

Correspondence may be sent to Steven Rosenzweig, M.D, Center for Integrative Medicine, Thomas Jefferson University, 1015 Chestnut Street, Suite 820, Philadelphia, PA 19107. E-mail:

steven.rosenzweig@mail.tju.edu

Background: Medical students confront significant academic, psychosocial, and existential stressors throughout their training. Mindfulness-based stress reduction (MBSR) is an educational intervention designed to improve coping skills and reduce emotional distress.

Purpose: The purpose of this study was to examine the effectiveness of the MBSR intervention in a prospective, nonrandomized, cohort-controlled study.

Methods: Second-year students $(n=140)$ elected to participate in a 10-week MBSR seminar. Controls $(n=162)$ participated in a didactic seminar on complementary medicine. Profile of Mood States (POMS) was administered preintervention and postintervention.

Results: Baseline total mood disturbance (TMD) was greater in the MBSR group compared with controls (38.7 \pm 33.3 vs. $28.0 \pm 31.2 ; p<.01)$. Despite this initial difference, the MBSR group scored significantly lower in TMD at the completion of the intervention period (31.8 \pm 33.8 vs. $38.6 \pm 32.8$; $p<.05$ ). Significant effects were also observed on Tension-Anxiety, Confusion-Bewilderment, Fatigue-Inertia, and Vigor-Activity subscales.

Conclusion: MBSR may be an effective stress management intervention for medical students.

The stresses of medical training are substantial. The ability to deal with a high degree of stress is a career-long necessity, impacting on personal wellness and the capacity to provide professional and compassionate patient care. Medical students contend with a range of personal stressors from their very first day. ${ }^{1-3}$ They confront academic stressors, working to master increasing quantities of information in limited periods of time. Medical students are subjected to new social stressors as they undergo professionalization; sacrifice time spent with loved ones; acquire sizable financial debt; and even face sexual harassment, racism, or professional abuse. ${ }^{4,5}$ Finally, students encounter powerful existential stressors as they meet the profound issues of human 
suffering and mortality. These academic, psychosocial, and existential stressors may lead to depression and suicide, anxiety, substance abuse and other pathological coping styles, damaged interpersonal relationships, ethical erosion, deidealization, and destabilized concepts of self and world. ${ }^{6-11}$ Mindfulness-based stress reduction (MBSR) has been shown to be an effective intervention for a range of populations ${ }^{12-15}$ including medical students.16 Mindfulness refers to nonjudgmental awareness of moment-to-moment experience. Through mindfulness practice, a person intentionally pays full attention to whatever is occurring in the present moment without judging it. Mindfulness practice cultivates concentration and insight, as well as physiologic relaxation. MBSR is an educational, group intervention that teaches a range of formal and informal mindfulness practices. $^{17}$

\section{Purpose}

The purpose of this study was to implement an MBSR intervention for 2nd-year medical students and measure its impact on the psychological well being of participants compared with a control group.

\section{Methods}

This was a prospective, nonrandomized, controlled trial. The study was approved by the institutional review board and verbal informed consent was obtained from all participants. All 2nd-year students at Jefferson Medical College during the years 1996 to 2000 were eligible to participate in a MBSR program, offered as one choice among approximately 10 elective seminars. Seminars were comprised of 10 weekly sessions, each providing 90 min of contact time.

During the MBSR course, a variety of mindfulness meditation practices were taught, including body scan, breath awareness, mindful stretching (Hatha Yoga), eating meditation, walking meditation, and guided imagery (mountain/lake meditations). Participants received an audiocassette for daily meditation practice and were expected to practice 20 min of formal meditation daily, 6 days per week.

Students in the control group participated in a seminar that surveyed complementary and alternative medicine. This course consisted of didactic sessions, demonstrations, group discussions, and brief student presentations. Although the topic of personal wellness is raised throughout the course, students are only introduced to mind-body techniques but not formally trained in them.

Three hundred two 2nd-year medical students participated in the study between fall 1996 and fall 2000. One hundred forty students received MBSR training, and 162 students served as parallel cohort controls. The average number of students who participated in MBSR in a given year (40) represented approximately 18\% of the entire 2nd-year medical student class. All study participants were in generally good health; however, neither physical nor mental health status was confirmed by formal examination. 
The Profile of Mood States (POMS) was administered to all participants at the beginning and end of the seminar. This instrument is a factor analytically derived inventory that measures six identifiable mood or affective states: Tension-Anxiety, DepressionDejection, Anger-Hostility, Vigor-Activity, Fatigue-Inertia, and ConfusionBewilderment.18 In addition to these six subscale scores, a total mood disturbance (TMD) score may be obtained from the POMS as a single, global measure of affective state by summing the scores across all six factors, weighting Vigor negatively. The POMS is sensitive to changes in mood as a result of therapeutic intervention or experimental manipulation. It has been validated in numerous study populations and exhibits good internal consistency ( 0.84 for Confusion to 0.95 for Depression) and testretest reliability ( 0.65 for Vigor to 0.74 for Depression). ${ }^{18}$

\section{Statistical Analysis}

Multivariate analysis of variance (MANOVA) for repeated measure design was used to examine pretest-posttest changes in the MBSR and control groups on all six POMS subscales simultaneously, to control for experimental-wise error. The TMD scores were not included in the MANOVA. Univariate analysis of variance (ANOVA) was used to detect significance of changes on TMD and also for examining within-group differences in the POMS subscale scores. Effect size estimates also were calculated using standardized mean pretest-posttest differences in MBSR and control groups to examine the clinical significance of observed changes. ${ }^{19}$

\section{Results}

\section{Effectiveness of Participation in the MBSR Program}

Repeated measures MANOVA, in which the POMS subscale scores were the dependent variables and group status (MBSR, control) was the independent variable, revealed a significant Group $\times$ Time interaction indicating a difference in preseminar-postseminar changes between the two groups $(p<.01)$. Based on this finding, univariate ANOVAs were performed to test for Group $\times$ Time interaction effects on each individual POMS subscale. The $p$ values for the interaction effect in two-way ANOVAs (for repeated measure design) reported in Table 1 indicate that the observed preseminar-postseminar changes between the MBSR and the control groups were statistically significant not only for the TMD scores $(p<.0001)$, but also for the Tension-Anxiety $(p<.0001)$, VigorActivity $(p<.0001)$, Fatigue-Inertia $(p=.0006)$, and Confusion-Bewilderment $(p=.02)$ subscales.

\section{Pretest-Posttest Differences Within Groups}

As shown in Table 1, univariate ANOVAs revealed decreases on the Tension-Anxiety ( $d$ $=-.23, p=.009)$ and Confusion-Bewilderment $(d=-.24, p=.009)$ subscales across the 10-week observation period in the MBSR group, whereas a statistically significant increase was found on the Vigor-Activity subscale $(d=.25, p=.006)$. TMD scores decreased by about seven points in the MBSR group $(d=-.18, p=.05)$. 
A different pattern of findings emerged in the control group. Postseminar scores revealed elevated Tension-Anxiety $(d=.28, p=.0008)$, Fatigue-Inertia $(d=.49, p<.0001)$, and $\operatorname{TMD}(d=.30, p=.0003)$, with a concurrent decrease on the Vigor-Activity subscale $(d$ $=-.47, p=.0001)$. Although the effect size estimates are small to moderate in magnitude, these findings nonetheless suggest that participation in the MBSR program improves psychological health, during a period of time in which mood disturbance may otherwise be expected to increase. The striking trend in opposite directions for the MBSR and control groups on the TMD scores is depicted in Figure 1.

At the conclusion of each MBSR seminar, students were asked to complete a course evaluation survey. Evaluations were available for 133 students. One hundred seventeen students (88\%) rated mindfulness practice as helpful or very helpful. Ninety-four students (71\%) reported being more “mindful” in day-to-day life. Eighty students (60\%) rated themselves as more effective in handling stressful situations as a result of the intervention. One hundred thirty (98\%) stated that they would recommend the MBSR course to other medical students and that they would refer patients to a similar program.

\section{Conclusions}

A recent review of clinical studies testing stress management interventions for medical trainees identified a range of interventions associated with positive outcomes. ${ }^{20} \mathrm{We}$ chose to study MBSR for several important reasons. First, there is substantial evidence supporting the efficacy of MBSR in reducing anxiety, depression, and somatization while enhancing participants' overall sense of well being. ${ }^{12-16}$ Second, MBSR teaches a broad skill set of formal and informal techniques that can be readily applied within the course of a typical workday. Third, MBSR provides a supportive group experience that in itself strengthens relationships among participants. Fourth, mindfulness practice has the potential to mitigate the full range of academic, social, and existential stressors experienced by medical students: Rather than being applicable only to particular situations, mindfulness practice informs an individual's response to the full range of experience. Mindfulness is, therefore, relevant throughout the lifetime of the physician and is arguably a core characteristic of clinical practice. ${ }^{21}$ Historically, mindfulness has been a foundation practice of major spiritual traditions and is uniquely suited to support medical professionals as they contend with the existential stressors of suffering and mortality. However, mindfulness practice is unencumbered by any sectarian belief system and is readily taught within a secular, biomedical culture.

Shapiro and colleagues ${ }^{16}$ conducted a randomized, wait-list control trial of MBSR in a mixed group of premedical and medical students. No significant differences were found between groups' pretest scores. However, postintervention the MBSR group reported significantly less depression, less anxiety, greater empathy, and greater sense of spirituality compared with controls. Our study demonstrates the effectiveness of MBSR in reducing psychological distress in a relatively large, homogeneous study population of medical students. Unlike Shapiro's study, however, group assignment was nonrandomized. This gave rise to a significant difference between intervention and 
control groups at baseline. Students with greater overall mood disturbance enrolled in the MBSR program. MBSR was successful in reducing mood disturbance in this self-selected population.

Table 1. Pretest and Posttest Total and Subscale Scores (Mean \pm SD) on the Profile of Mood States (POMS), and Summary Statistical Results

\begin{tabular}{|c|c|c|c|c|c|c|c|c|c|}
\hline \multirow[b]{2}{*}{ POMS Scales } & \multicolumn{4}{|c|}{ MBSR Group $^{a}$} & \multicolumn{4}{|c|}{ Control Group } & \multirow[b]{2}{*}{$\begin{array}{c}\text { Interaction } \\
\text { pe }\end{array}$} \\
\hline & Pre & Post & dc & $p d$ & Pre & Post & dc & pd & \\
\hline Tension-Anxiety & $14.5 \pm 7.2$ & $12.4 \pm 7.0$ & -0.23 & 0.009 & $11.3 \pm 6.3$ & $13.4 \pm 6.9$ & 0.28 & 0.0008 & $<0.0001$ \\
\hline Vigor-Activity & $14.8 \pm 5.8$ & $16.3 \pm 5.6$ & 0.25 & 0.006 & $17.4 \pm 5.6$ & $14.2 \pm 5.6$ & -0.47 & 0.0001 & $<0.0001$ \\
\hline Fatigue-Inertia & $10.2 \pm 6.3$ & $10.6 \pm 6.2$ & 0.06 & 0.50 & $8.4 \pm 5.3$ & $11.8 \pm 6.2$ & 0.49 & 0.0001 & 0.0006 \\
\hline Confusion-Bewilderment & $10.0 \pm 5.6$ & $9.3 \pm 4.8$ & -0.24 & 0.009 & $9.1 \pm 4.7$ & $9.3 \pm 4.8$ & 0.05 & 0.52 & 0.02 \\
\hline Depression-Dejection & $10.4 \pm 10.0$ & $8.8 \pm 9.0$ & -0.15 & 0.09 & $8.8 \pm 9.0$ & $9.5 \pm 8.6$ & 0.07 & 0.37 & 0.06 \\
\hline Anger-Hostility & $8.5 \pm 6.8$ & $7.8 \pm 7.3$ & -0.08 & 0.38 & $7.8 \pm 7.8$ & $8.9 \pm 8.1$ & 0.12 & 0.13 & 0.09 \\
\hline Total Mood Disturbance & $38.7 \pm 33.3$ & $31.8 \pm 33.8$ & -0.18 & 0.05 & $28.0 \pm 31.2$ & $38.6 \pm 32.8$ & 0.30 & 0.0003 & $<0.0001$ \\
\hline
\end{tabular}

Note: Multivariate $\mathrm{F}_{(6,270)}=7.68$; Wilks' Lambda $=0.85, p<0.01$.

${ }^{\mathrm{a}} n=125 .{ }^{\mathrm{b}} n=152$. ${ }^{\mathrm{c}} d$ is the effect size estimate (standardized mean difference) for pre-post seminar change scores. ${ }^{\mathrm{d}} p$ values for obtained mean differences using univariate analysis of variance (ANOVA). ${ }^{\mathrm{e}} p$ values for interaction effects of group by pre-post seminar scores resulted from 2-way ANOVAs for repeated measure design.

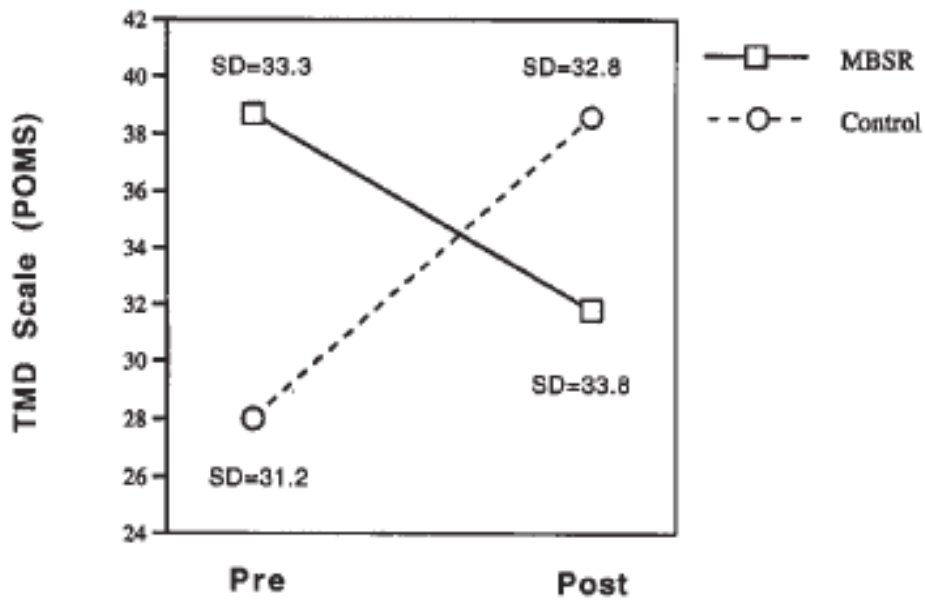

Figure 1. Pre- and postintervention mean scores on the Total Mood Disturbance (TMD) scale of the Profile of Mood States (POMS). The MBSR group experienced an 18\% decrease in overall psychological distress, whereas the control group experienced a 38\% increase during the 10-week observation period $(p<.01)$. 
A striking, inverse trend in mood change emerged between MBSR and control groups over the course of the study period (Figure 1). Seminars concluded as students approached final examinations, a period of increased stress during which healthy medical students will manifest clinically significant anxiety symptoms. ${ }^{22}$ Our cohort controls demonstrated a marked increase in TMD scores at this time. In contrast, participants in the MBSR group demonstrated not only significant improvement over baseline scores but had significantly lower, final TMD scores compared with controls. This finding supports Shapiro's16 study, which showed that the MBSR group demonstrated a stable level of anxiety over time, whereas the control group's anxiety scores increased significantly.

Academic pressures may create a significant barrier to student participation in extracurricular stress reductions programs. Many students believed they would have not surrendered study time to attend an after-hours MBSR program. In this study, MBSR was offered as an optional pathway within the required curriculum structure and, therefore, did not require extra time commitment.

This study is limited by several factors. First, randomization was not employed; thus, there were differences in overall psychological distress between the intervention and control groups at baseline. Second, unlike the MBSR group, the control group did not have a 20-min daily home assignment. Third, neither of the groups may be truly representative of the general medical student population. We chose to use the complementary and alternative medicine seminar as a control group because, among all the seminars offered, it was the most similar in terms of educational content; the control group did learn about mind-body medicine and alternative healing philosophies but did not train in any mind-body practice. Lastly, only a single instrument, the POMS, was used as an outcome measure. MBSR has been shown to effect changes in a wide range of parameters, including a reduction of somatization, bodily pain, improvement in social functioning, increased empathy, and enhanced sense of spirituality. ${ }^{12-15}$ Given the range of physical and psychosocial changes that may occur with MBSR practice, it is important that future studies within the medical student population evaluate a broader range of outcomes, including the correlation of stress reduction with academic and clinical performance.

In summary, we reported on a 5-year study of MBSR as a stress management intervention for 2nd-year medical students. Students who self-selected for the MBSR intervention reported greater overall mood disturbance at baseline compared with parallel cohort controls. At the conclusion of the intervention, however, students in the MBSR group reported significant improvement in mood states and reported significantly lower psychological distress compared with controls. We conclude that MBSR may be an effective stress management intervention for medical students.

\section{References}

1. Guthrie EA, Black D, Shaw CM, Hamilton J, Creed FH, Tomenson B. Embarking upon a medical career: Psychological morbidity in first year medical students. Medical Education 1995;29:337-41. 
2. Stewart SM, Betson C, Lam CH, Marshall IB, Lee PWH, Wong CM. Predicting stress in first year medical students:A longitudinal study. Medical Education 1997;31:163-8.

3. Hojat M, Gonnella JS, Erdmann JB, Vogel WH. Medical students' cognitive appraisal of stressful life events as related to personality, physical well-being, and academic performance: A longitudinal study. Personality and Individual Differences 2003 (in press).

4. Silver HK, Glicken AD. Medical student abuse: Incidence, severity, and significance. Journal of the American Medical Association 1990;263:527-32.

5. Sheehan KH, Sheehan DV, White K, Leibowitz A, Baldwin DC Jr. A pilot study of medical student "abuse": Student perceptions of mistreatment and misconduct in medical school. Journal of the American Medical Association 1990;263:533-7.

6. Rosal MC, Ockene IS, Ockene JK, Barrett SV, Ma Y, Herbert JR. A longitudinal study of students' depression at one medical school. Academic Medicine 1997;72:542-6.

7. Richings JC, Khara GS, McDowell M. Suicide in young doctors. British Journal of Psychiatry 1986;149:475-8.

8. Cockrell K. An overview of physician impairment. Indiana Medicine 1991;84:274-5.

9. Dickstein LJ, Stephenson JJ, Hinz LD. Psychiatric impairment in medical students. Academic Medicine 1990;65:558-93.

10. Feudtner C, Christakis DA, Christakis NA. Do clinical clerks suffer ethical erosion? Students' perceptions of their ethical environment and personal development. Academic Medicine 1994;69:670-9.

11. Kay J. Traumatic deidealization and the future of medicine. Journal of the American Medical Association 1990;263:572-3.

12. Reibel DK, Greeson JM, Brainard GS, Rosenzweig S. Mindfulness-based stress reduction and health-related quality of life in a heterogeneous patient population. General Hospital Psychiatry 2001;23:183-92.

13. Kabat-Zinn J, Lipworth L, Burney R, Sellers W. Four-year follow-up of a meditation-based program for the self-regulation of chronic pain: Treatment outcomes and compliance. Clinical Journal of Pain 1986;2:159-73.

14. Miller J, Fletcher K, Kabat-Zinn J. Three-year follow-up and clinical implications of a mindfulness-based stress reduction intervention in the treatment of anxiety disorders. General Hospital Psychiatry 1995;17:192-200.

15. Astin JA. Stress reduction through mindfulness meditation. Psychotherapy and Psychosomatics 1997;66:97-106.

16. Shapiro SL, Schwartz GE, Bonner G. Effects of mindfulness-based stress reduction on medical and premedical students. Journal of Behavioral Medicine 1998;21:581-99.

17. Kabat-Zinn J. Full catastrophe living. New York: Dell Publishing, 1990.

18. McNair DM, Lorr M, Droppleman LF. Manual for the Profile of Mood States. San Diego, CA: EdITS/Educational and Industrial Testing Service, 1992.

19. Cohen J. Statistical power analysis for behavioral sciences. Hillsdale, NJ: Lawrence Erlbaum Associates, Inc., 1987. 
20. Shapiro SL, Shapiro DE, Schwartz GER. Stress management in medical education: A review of the literature. Academic Medicine 2000;75:748-59.

21. Epstein RM. Mindful practice. Journal of the American Medical Association 1999;282:833-8.

22. Pitts FN, Winokur G, Stewart MA. Psychiatric syndromes, anxiety symptoms and responses to stress in medical students. American Journal of Psychiatry 1961;118:333-40. 